Contract No. and Disclaimer:

This manuscript has been authored by Savannah River Nuclear Solutions, LLC under Contract No. DE-AC09-08SR22470 with the U.S. Department of Energy. The United States Government retains and the publisher, by accepting this article for publication, acknowledges that the United States Government retains a non-exclusive, paid-up, irrevocable, worldwide license to publish or reproduce the published form of this work, or allow others to do so, for United States Government purposes. 


\title{
SRNL-STI-2010-00150 \\ PACKAGING AND TRANSPORTATION OF ADDITIONAL NEPTUNIUM OXIDE
}

\author{
Robert W. Watkins, Stephen J. Hensel, and Jeffrey M. Jordan \\ Savannah River National Laboratory \\ Aiken, SC 29808
}

\begin{abstract}
The Savannah River Site's HB-Line Facility completed a second neptunium oxide production campaign in which nine (9) additional cans of neptunium oxide were produced and shipped to the Idaho National Laboratory and Oak Ridge National Laboratory in the 9975 shipping container. These additional cans were from a different feed solution than the first fifty (50) cans of neptunium oxide that were previously produced and shipped via a Letter of Amendment to the 9975 Safety Analysis Report for Packaging (SARP) content table. This paper will address the challenges associated with demonstrating the neptunium oxide produced from the additional feed solution was equivalent to the original neptunium oxide and within the content description of the Letter of Amendment.
\end{abstract}

\section{Introduction}

Neptunium-237 oxide is used for the production of plutonium-238 to support NASA space missions. Previous chemical processing at the Savannah River Site (SRS) H-Canyon Facility during the 1970s and 1980s produced neptunium solutions. These solutions were stored in a $\mathrm{H}$ Canyon tank until 2003 when the decision was made to stabilize the solutions into neptunium237 oxide to support future plutonium-238 production. Processing the solutions into neptunium oxide would be performed in the HBLine Facility at the Savannah River Site (SRS).

The HB-Line Facility completed a campaign in which a total of fifty nine (59) cans of neptunium oxide were produced and shipped to the Idaho National Laboratory (INL) and Oak Ridge National Laboratory (ORNL) in the 9975 shipping container. The shipping campaign involved the addition of neptunium oxide to the Model 9975 B(M)F-85 Safety Analysis Report for Packaging (9975 SARP) as a new content and then a Letter of Amendment to the 9975 SARP content table. The first fifty (50) cans of neptunium oxide was produced from H-Canyon Tank 8.5 solution (referred to as Neptunium Part 1). Shipment of Neptunium Part 1 material is addressed in ASME Paper "Packaging and
Transportation of Neptunium Oxide" by the authors.

The remaining nine (9) cans of neptunium oxide were produced from H-Canyon Tank 16.4, 11.7, 12.5, and 9.6 (referred to as Neptunium Part 2) after all of the Part 1 solution was converted to oxide. These additional cans were from a different feed solution than the original fifty (50) cans of neptunium oxide that were previously produced and shipped via a Letter of Amendment to the 9975 Safety Analysis Report for Packaging (SARP) content table. Eight of the Neptunium Part 2 oxide cans were shipped to INL and one Neptunium Part 2 oxide can was shipped to ORNL under the same SARP Letter of Amendment that authorized the shipment of the Neptunium Part 1 material.

\section{Neptunium Oxide Process}

Neptunium nitrate solution from the H-Canyon Facility was transferred to the HB-Line Facility were it was concentrated, purified, and then converted to an oxide powder. The H-Canyon feed material was approximately $13 \mathrm{~g} / \mathrm{l}$ neptunium. Ferrous sulfamate was added to the neptunium feed to ensure the neptunium valence was adjusted to +4 . After adjusting the molarity, the solution was transferred to an anionexchange resin column. Approximately $2000 \mathrm{~g}$ of neptunium was loaded on the anion column per batch. The anion exchange concentrated and purified the neptunium nitrate solution to approximately $50 \mathrm{~g} / \mathrm{l}$ neptunium. The neptunium nitrate was then heated and transferred to a precipitator. Oxalic acid was added to the neptunium solution in a direct strike precipitation process. The precipitant was collected on a screen in a "filter boat". The neptunium oxalate precipitant was calcined in a furnace to form neptunium oxide powder. The oxalate was heated above $635^{\circ} \mathrm{C}$ for 3 hours in air to form approximately $1200 \mathrm{~g}$ of neptunium oxide per filter boat. The neptunium oxide was packaged in sealed product cans, with approximately $6 \mathrm{~kg}$ neptunium per can, which were loaded into a 9975 shipping container for shipment from SRS to INL and ORNL 
Unlike the Part 1 solution from Tank 8.5, which was primarily pure neptunium solution with some plutonium and trace amounts of nonradioactive impurities, the Part 2 solution was a collection of solutions from various tanks that contained low concentrations of plutonium and uranium solutions with neptunium. Prior to HBLine receiving the Part 2 solution, the contents were processed by the H-Canyon solvent extraction process to "clean-up" the neptunium solution for the purpose of making the solution resemble the Part 1 solution. The processing removed most of the unwanted constituents (plutonium, thorium, cerium, and some nonradioactive impurities) and yielded a "clean" neptunium solution. To reduce the possibility that the solution would become contaminated by tank heels and process piping as it is moved through the H-Canyon to the HB-Line feed tank, a flush program was implemented by H-Canyon.

The Part 2 solution was processed in HB-Line using a similar flow sheet as the Part 1 solution. The only change was that additional anionexchange column washes were implemented to remove the large amounts of uranium that could not be removed by H-Canyon which would carry over into the neptunium oxide product. Although the additional column washes were necessary to avoid a neptunium oxide product with a low neptunium assay which could not be reprocessed or shipped, the washes did result in the lose of some neptunium resulting in less cans of neptunium oxide.

\section{SARP Letter of Amendment}

The Letter of Amendment to the 9975 SARP established neptunium content criteria which would be safe to ship in a 9975 shipping container and could be achieved by the HB-Line Facility. The 9975 SARP Letter of Amendment defined in detail specific limits for radioactive material, non-radioactive impurities, moisture, and physical characteristics.

For the shipment of any actinide material in oxide form, such as neptunium oxide, gas generation must be addressed. The primary parameters associated with gas generation of the neptunium oxide product are moisture content and total alpha dose (or activity). Gas generation testing of plutonium oxide has shown that specific surface area (SSA) and moisture content are two important factors in hydrogen (and oxygen) gas generation of plutonium oxide. For plutonium oxide, SSA and moisture uptake decrease with increasing temperature used to calcine the material. Neptunium oxide was expected to behave similarly.

Prior to commencement of neptunium processing, a liquid sample of H-Canyon neptunium solution was converted to neptunium oxide at the Savannah River National Laboratory (SRNL) to determine the neptunium oxide hydrogen gas generation rates and provide input to the 9975 SARP content table. The neptunium oxide was produced according to the anticipated HB-Line flowsheet (process) consisting of anion exchange, oxalate precipitation, filtration, and calcination. Characterization of the neptunium oxide product to be used in gas generation tests included bulk and tap density measurements, Xray diffraction, particle size distribution, specific surface area measurements, and moisture analysis. Temperatures of $600^{\circ} \mathrm{C}$ and $650^{\circ} \mathrm{C}$ were chosen to calcine the neptunium oxalate based on the expected HB-Line furnace operating temperature of $625^{\circ} \mathrm{C}+/-25^{\circ} \mathrm{C}$.

The neptunium oxide Letter of Amendment to the 9975 SARP included new content limits for neptunium oxide such as specifying a moisture limit in terms of LOI to be less than $0.24 \mathrm{wt} \%$, limiting the total plutonium content to no more than $611 \mathrm{ppm}$, limiting the total plutonium alpha activity to no more than 8,580 microcuries per gram of neptunium, and specifying only a total non-radioactive impurity limit. In addition, the neptunium oxide had to be produced by a method equivalent to original neptunium oxide. The original neptunium oxide limits for material inerting, total material mass, total radioactive material mass, and heat generation (watts) from the 9975 SARP were unchanged.[1]

\section{Neptunium Oxide Subject Matter Expert Team}

For Neptunium Part 2, a Neptunium Subject Matter Expert (SME) Team was formed to verify compliance with the requirements of the 9975 SARP Letter of Amendment. The purpose of the SME Team was to establish the criteria against which the Neptunium Part 2 solutions and final product could be judged to show equivalency with the Neptunium Part 1 solution and final product in regard to the impurities and physical attributes of the final product. 
The Savannah River Site (SRS) produced neptunium oxide from two different solution sources. The Part 1 feed solution was used as the basis for the original neptunium oxide content evaluations which were incorporated into the 9975 SARP. This evaluation included gas generation testing on laboratory produced neptunium oxide from the Part 1 solution. A Letter of Amendment to the 9975 SARP was written after process upsets prevented the processing facility from meeting the original content requirements as specified in the SARP. The basis for the Letter of Amendment was the determination of the parameters which were key to gas generation. These were moisture content, alpha activity, and material purity. Also included in this Letter of Amendment was justification to allow the neptunium oxide product produced from the Part 2 feed solution to be shipped in a 9975, provided this product could be shown equivalent to the Part 1 neptunium oxide product.

Since gas generation testing could not be performed for the neptunium oxide from the Part 2 solution, a Neptunium SME Team was established to determine what parameters the Part 2 solution and oxide product had to meet. To answer this question the Neptunium SME Team determined the composition of the Part 1 material at three stages: the initial solution, the in-process solution, and the final neptunium oxide product. From these compositions the Neptunium SME Team established the criteria by which the Part 2 material would be compared to the Part 1 material. Trigger limits for impurities were established for each stage. Any impurity above the specified trigger limit had to be evaluated by the Neptunium SME Team. Provided the Part 2 material final neptunium oxide product compared favorably to the neptunium oxide product from the Part 1 material it was deemed by the Neptunium SME Team to be bounded by the gas generation testing of the Part 1 product which satisfied one of the Letter of Amendment conditions for shipment.

The initial solution and in-process solution comparisons were done to ensure that any impurities which would affect the final neptunium oxide product were removed since reprocessing the oxide was not an option. As expected, the initial solution had significant levels of uranium which confirmed the need for additional anion-exchange column washes to remove the uranium which would carry over with neptunium oxide and yield an undesirable product. The other elements that exceeded the initial solution trigger limits were iron, sodium, chromium, and nickel. The SME Team concluded that these elements would be removed by the HB-Line process and not significantly impact the neptunium oxide product. The inprocess solution results showed reduced levels of uranium, sodium, and iron which were well within the SME trigger limits. Chromium and nickel still remained above the SME trigger limits along with cerium and magnesium. The SME Team anticipated some carry over of these elements into the final oxide product; however, small changes in the concentration of these metals were not expected to cause a significant change in hydrogen generation rate of the neptunium oxide product.

The Neptunium SME reviews of the final oxide product primarily focused on product purity, alpha activity, moisture content, and impurity results verses the trigger limits. This review was conducted for each of the neptunium oxide cans produced from the Part 2 feed solution. Although some of the neptunium oxide product cans produced from the Part 2 feed solution did occasionally exceed the impurity trigger limits, all of the cans were deemed within the original gas generation testing and acceptable for shipment. When an impurity trigger limit was exceeded the Neptunium SME Team evaluated the neptunium oxide product against the following questions:

- What was the impurity that exceeded the trigger limit?

- How much above the trigger limit was the impurity result?

- Is there an increasing or decreasing trend for the impurity results?

- What effect does the impurity have on gas generation?

- What was the neptunium assay (purity)?

- What was the alpha activity?

- What was the moisture content (level)?

All nine of the Neptunium Part 2 cans had very favorable results for moisture, alpha activity, and neptunium assay. However, all nine neptunium oxide cans had at least one impurity result that exceeded the trigger limit. Cerium consistently exceeded the trigger limit as expected since cerium was above the trigger limit in the inprocess solution. In an oxalate precipitation 
process cerium converts to cerium oxide, during furnace conversion. Because cerium oxide is a refractory oxide the SME Team did not expect it to cause a significant change in hydrogen generation of the neptunium Part 2 oxide. The trigger limits for cadmium and lithium were exceeded slightly only once for different neptunium oxide cans. Considering the high neptunium assay, low moisture, and low alpha activity the SME Team concluded the hydrogen generation rate for the neptunium oxide to remain within the test results of the neptunium Part 1 oxide.

The biggest challenge for the SME Team came from the carbon results. The carbon results for the third can were slightly above the trigger limits. For the next four cans the carbon results remained above the trigger limits but showed a puzzling increasing then decreasing trend. Based on analysis of carbon components within the HB-Line process (i.e. anion resin, gaskets), it appeared that the carbon was not organic and consequently was not anticipated to change the hydrogen generation of this neptunium oxide product significantly. However, neither the source nor the form of the carbon had been identified; therefore, the Neptunium SME Team developed additional lines of inquiry to investigate the elevated carbon in the neptunium oxide. Fortunately an investigation into the carbon analytical protocols revealed that the site laboratory carbon results were biased high in regards to the Part 2 Neptunium Oxide.

After answering each of these questions, the Neptunium SME Team concluded that the neptunium oxide from the Part 2 feed solution was equivalent to the neptunium oxide produced from the Part 1 feed solution campaign with respect to the impurities and physical attributes affecting gas generation. [2]

\section{Conclusion}

The Neptunium SME Team determined that the Savannah River Site's HB-Line Facility Part 2 Neptunium Oxide production campaign oxide was equivalent to the Part 1 Neptunium Oxide campaign with respect to impurities and physical attributes for hydrogen gas generation. Therefore, the SME Team concluded that the neptunium oxide meet the chemical composition criteria for shipment to the Idaho National Laboratory and Oak Ridge National Laboratory per the Letter of Amendment to the 9975 SARP. The successful shipment of nine (9) additional cans of neptunium oxide marked the conclusion to the SRS neptunium stabilization campaign. In total fifty nine (59) cans of neptunium oxide were produced and shipped to the Idaho National Laboratory and Oak Ridge National Laboratory in the 9975 shipping container.

\section{References}

1. R. W. Watkins, S. J. Hensel, and J. M. Jordan, PVP2009-77200, SRNS-STI-2009-00166, "Packaging and Transportation of Neptunium Oxide”

2. R. W. Watkins, D. R. Leduc, and N. M. Askew, 09-LA-540-INMM, SRNL-STI-200900418, “New Approach to Addressing Gas Generation in Radioactive Material Packaging” 